\title{
Health labelling can influence taste perception and use of table salt for reduced-sodium products
}

\author{
Djin Gie Liem ${ }^{1, *}$, Fatemeh Miremadi ${ }^{1}$, Elizabeth H Zandstra ${ }^{2}$ and Russell SJ Keast ${ }^{1}$ \\ ${ }^{1}$ School of Exercise and Nutrition Sciences, Sensory Science Group, Faculty of Health, Deakin University, \\ Burwood Highway, Burwood, VIC 3125, Australia: ${ }^{2}$ Sensation, Perception \& Behaviour, Unilever R\&D \\ Vlaardingen, Vlaardingen, The Netherlands
}

Submitted 21 September 2011: Accepted 20 January 2012: First published online 8 March 2012

\begin{abstract}
Objective: To investigate the effect of front-of-pack labels on taste perception and use of table salt for currently available and sodium-reduced soups.

Design: Within-subject design.

Setting: Sensory laboratory.

Subjects: Participants ( $n$ 50, mean age $34 \cdot 8$ (sD 13.6) years) were randomly served nine soups ( $250 \mathrm{ml}$ each) across $3 \mathrm{~d}$. Servings differed in: (i) health label (i.e. no health label, reduced-salt label or Heart Foundation Tick); and (ii) sodium reduction (no reduction - benchmark, 15\% less sodium or 30\% less sodium). Before tasting, participants rated their expected salt intensity and liking. After tasting, participants rated their perceived salt intensity and liking, after which they could add salt to the soup to make it more palatable.

Results: Reduced-salt labels generated a negative taste expectation and actual taste experience in terms of liking $(P<0.05)$ and perceived saltiness $(P<0.05)$. Perceived saltiness of sodium-reduced soups decreased more $(P<0 \cdot 05)$, and consumers added more salt $(P<0 \cdot 05)$, when soups carried the reduced-salt label. The tick logo and soups without health labels had no such influence on taste perception.

Conclusions: Emphasizing salt reduction by means of a front-of-pack label can have a negative effect on taste perception and salt use, especially when consumers are able to taste differences between their regular soup and the sodium-reduced soup. Overall health logos which do not emphasize the reduction in salt are less likely to affect perceived salt intensity and therefore are viable solutions to indicate the healthiness of sodium-reduced products.
\end{abstract}

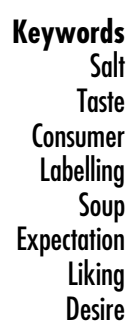

Australian consumers are well informed and seem to be increasingly aware of the association between diet and health $^{(1)}$. A recent study suggests that $88 \%$ of Australian consumers are aware of the association between high sodium intake and elevated blood pressure, but a minority (44\%) were worried about their sodium intake or were aware (27\%) of the upper limit of daily sodium intake set by the Australian National Heart Foundation ${ }^{(2)}$, which makes it difficult for them to understand nutrition information panels which are placed on food products.

To assist consumers in making healthier food choices several initiatives are taken. First, some food products carry nutrient labels on the front of the pack, such as 'low in salt' ${ }^{(3)}$, which may attract the attention of healthconscious consumers ${ }^{(3,4)}$. In Australia nutrient claims and labels are regulated by the Australia New Zealand Food Standards Code which, for example, states that a 'low salt' label is only permitted on foods which do not contain more than $120 \mathrm{mgNa} / 100 \mathrm{~g}^{\text {food }}{ }^{(5)}$. Health claims in relation to sodium reduction are not permitted by the
Code. Second, some food products carry a front-of-pack health logo, which enables consumers to make quick and healthier food choices ${ }^{(6,7)}$. In 1989 the Australian Heart Foundation initiated the 'Pick-the-Tick' programme. A manufacturer can apply for a Tick by submitting a proposal to the Heart Foundation, which reviews the proposal according to predetermined criteria $\left(\right.$ see $\left.^{(8,9)}\right)$. Ten years after the introduction of the Pick-the-Tick programme, 89\% of Australian consumers recognized the Tick logo and the majority (59\%) reported to buy products with this $\operatorname{logo}^{(9)}$.

Although nutrient labels as well as health logos aim to assist consumers in making a healthier choice, they may not attract consumers who are more concerned about taste than health. It has been suggested that health-conscious consumers are more likely to buy products with healthy choices logos compared with taste-focused consumers ${ }^{(10)}$. This may generate a potential unexpected side-effect of nutrient labels and healthy choice logos. Some consumers may deliberately avoid products with nutrient labels and/or healthy choice logos, because they expect these products to 
be inferior in taste ${ }^{(6)}$. Information given alongside food may trigger different areas of the brain in such a way that information associated with a bad taste triggers brain areas also known to be activated by the smell of a bad odour ${ }^{(11)}$.

In a study with margarines, it was found that consumers who held positive beliefs about full-fat spread judged margarines which carried a 'full fat' label as more pleasant, smoother and having better mouthfeel than identical margarines which were labelled as 'reduced fat' ${ }^{\text {(12) }}$. Similar results were also obtained with soups ${ }^{(13)}$. We previously suggested that labels such as 'reduced in salt' negatively impacted on expected saltiness, but not perceived saltiness of non-sodium-reduced soups ${ }^{(14)}$. It is yet unknown how nutrient labels and healthy choices logos affect the perception of products which are noticeably different from consumers' normal products due, for example, to sodium reduction.

Hypothetically, the discrepancy in terms of liking and perceived saltiness between consumers' normal product and the reduced-sodium product can be increased when consumers expect products to be less salty and/or tasty. This is called assimilation. During assimilation, consumers' perception is biased towards their expectations ${ }^{(15,16)}$. Lange et al. suggested that when differences (induced by the type of information) between blind ratings and expectations of identical orange juices were large, consumers moved their ratings towards their expectations ${ }^{(17)}$. A similar phenomenon may happen when consumers taste a variety of sodiumreduced soups while seeing different health- and nutrientrelated labels, which alter consumers' expectations of the taste of the products in the direction of their expectations.

The present study investigated the influence of nutrient labels (i.e. 'Now reduced in salt, great taste') and a health logo (i.e. Pick-the-Tick) on expected and perceived taste perception of sodium-reduced soups. It is hypothesized that with an increase in sodium reduction, the negative taste effects of a nutrient label and health logo will increase as well.

\section{Experimental methods}

\section{Participants}

Participants were recruited by means of flyers in public places. Those who reported to be allergic to the ingredients present in the test products were excluded. This resulted in fifty participants (thirty-three females; mean age $34 \cdot 8$ (sD $13 \cdot 6$ ) years) who completed all sessions for which they received a \$AUD 15 gift voucher after each session. The study was approved by the Human Ethics Committee of Deakin University (HEAG-H 180/09).

\section{Materials}

\section{Soups}

Three soups varying in sodium content were included in the study: (i) benchmark product, which was an Australian commercially available chicken noodle soup $(305 \mathrm{mg} \mathrm{Na} /$ $100 \mathrm{ml}$ prepared soup); (ii) $15 \%$ sodium-reduced soup ( $259 \mathrm{mg} \mathrm{Na} / 100 \mathrm{ml}$ prepared soup); and (iii) 30\% sodiumreduced soup ( $213 \mathrm{mg} \mathrm{Na} / 100 \mathrm{ml}$ prepared soup. The recipe for all soups was the same (per $100 \mathrm{ml}$ prepared soup: energy $75 \cdot 2 \mathrm{~kJ}$, protein $0.44 \mathrm{~g}$, total fat $0.24 \mathrm{~g}$, saturated fat $0.04 \mathrm{~g}$, carbohydrates $3.4 \mathrm{~g}$, sugar $0.6 \mathrm{~g}$ ); only the sodium content was different. All soups contained: noodles, maltodextrin, salt, sugar, flavours (containing milk derivatives), flavour enhancers $(621,627)$, sunflower oil, parsley, potassium chloride, turmeric and spice extract. The soups were especially produced for the purpose of the current study (Unilever Sydney, Australia).

Quantitative Descriptive Analysis was performed with seven trained panellists (six females, mean age 51 (SD 15) years) to assess sensory profiles (see Meilgaard et al. ${ }^{(18)}$ for more details). This resulted in seventeen attributes to describe the flavour of the soup. Individual sensory testing of the three chicken noodle soups (i.e. benchmark, $-15 \%$ and $-30 \%$ sodium reduction), in duplicate, commenced once panellists were able to rate the intensity of the seventeen attributes reliably within and between panellists (see Meilgaard et al. ${ }^{(18)}$ for more details). Figure 1 shows the sensory profile of the three chicken noodle soups.

\section{Labels, bowls and salt shakers}

Professionally produced labels (Red Gecko Design, Sydney, Australia) were placed on the different pouches of dry soups in such a way that the experimental labels had a similar layout and look to the commercially sourced soup labels. Soups (benchmark, $-15 \%$ and $-30 \%$ sodium reduction) were provided with one of the three different labels: (i) no health label; (ii) a nutrient label stating 'Now reduced in salt, great taste' (hereafter referred to as the 'reduced-salt label'); and (iii) a health logo, the Heart Foundation Tick (hereafter referred to as the 'tick label'; see Fig. 2). Each combination of label and soup was given once (3 labels $\times 3$ soups), which resulted in nine samples for tasting. Soups were tasted from polystyrene double-layered bowls, which were designed to minimize the cooling down of the soups and could hold up to $350 \mathrm{ml}$ of soup. Plastic spoons were provided to the participants. Furthermore, participants were provided with commercially sourced salt shakers which contained $50 \mathrm{~g}$ of salt (Saxa table salt shakers, $8 \mathrm{~cm} \times 4 \mathrm{~cm}$, nine holes). Salt shakers were weighed, on a digital scale with microgram accuracy (model X3-310D; Denver Instrument), before and after participants tasted the soup. The salt shaker provided on average $0.04 \mathrm{~g}$ salt per shake.

\section{Sensory measures}

Expected and perceived saltiness were measured with a 9-point just-about-right scale which combines intensity and hedonic judgements and was previously designed to assess consumers' response to a specific attribute ${ }^{(19)}$. On this scale $1=$ 'not salty enough at all', $5=$ 'just about 


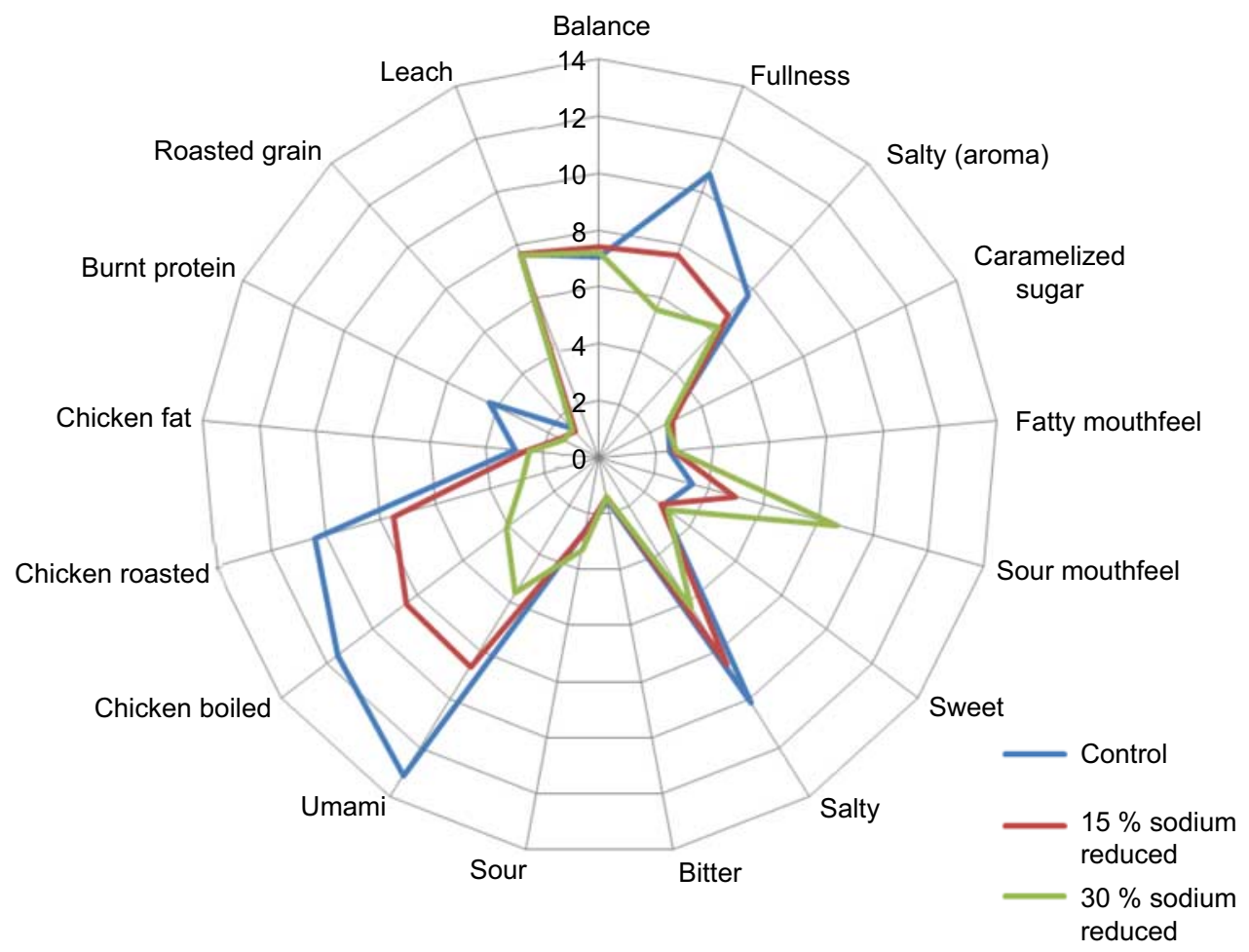

Fig. 1 (colour online) Sensory profile of the benchmark, 15\% and 30\% sodium-reduced soups as determined by Quantitative Descriptive Analysis among seven panellists ( $0=$ 'not strong at all', $14=$ 'extremely strong')

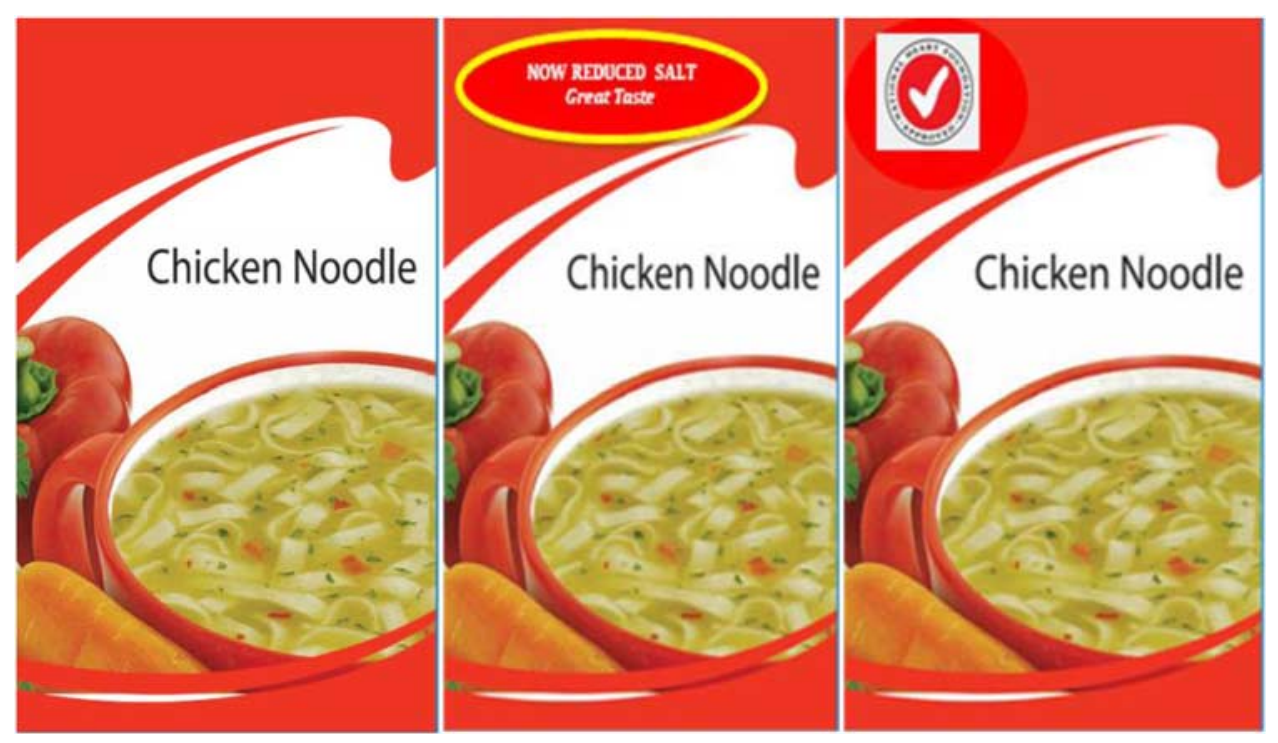

Fig. 2 (colour online) Packages (left, no health label; middle, reduced-salt label; right, tick label) that were shown to the participants prior to and during the tasting of the soups

the right amount of salt for me' and $9=$ 'far too salty for me'. Expected and perceived liking were measured with a 9-point hedonic scale ranging from $1=$ 'not liked at all' to $9=$ 'extremely liked'. All sensory data were collected using CompuSense software version 5 (Compusense Inc., Guelph, ON, Canada).

\section{Procedure}

Consumers came to the university for a half-hour session on the same day and time once weekly for 3 weeks. Tasting took place in the sensory booths of the university, which minimized interaction between participants while they tasted the soups. At the start of each session participants 
were shown a package of soup and were asked whether they would like to buy this soup and what they expected of the liking, desire and saltiness of this soup. Subsequently, they were instructed to open the pack and empty the content in a soup bowl. The researcher then added boiling water to a total of one serving $(250 \mathrm{ml})$ of soup. Participants were instructed to taste one spoonful of the soup when it was cooled down to about $65^{\circ} \mathrm{C}$, which was verified with a laser thermometer for each soup (model VZ8895NL, range -40 to $800^{\circ} \mathrm{C}$; $\mathrm{AZ}$ Instruments). While tasting the soup, participants were asked to rate the soup on perceived liking and salt intensity. After tasting and rating the soup, participants were given a salt shaker with $50 \mathrm{~g}$ of salt and were instructed to add as much salt as they wanted up to their maximum liking. Participants were allowed to taste the soup while they were adding salt and were free to decide not to add any salt at all. In total, participants tasted nine soups in a randomized order during three sessions on three separate days in such way that they received one pack with no label, one pack with the reduced-salt label and one pack with the tick label each day. Every consumer received a unique order; no order was given more than once. Between sessions, participants were instructed to rinse their mouth with water three times.

\section{Statistical analysis}

To assess the strength and direction of the association between expectations and actual perception, Spearman correlation coefficients were calculated between expected liking and perceived liking and between expected salt intensity and perceived salt intensity. In order to determine differences in expected liking, one-way repeatedmeasures ANOVA (according to the within-subject design) were conducted to determine significant differences between (i) soups with different labels and (ii) soups with the same label given during the three testing days. A similar analysis was conducted to determine differences in perceived liking after participants tasted the soups.

We hypothesized that consumers were more likely to buy and consume a soup with an ideal saltiness than a soup with a less ideal saltiness, so therefore it was important to assess whether soups were perceived as significantly different from their ideal saltiness. In order to determine whether the expected and perceived salt intensity significantly differed from the 'just about right' value of 5 , one-sample $t$ tests were conducted with 5 as the set value.

For those who added salt after tasting the soups, a sodium compensation score was calculated by adding the amount of sodium consumers added to the amount of sodium present in the soup; this resulted in the total amount of sodium. The total amount of sodium was then expressed as a percentage of the total amount of sodium present in the benchmark minus 100. For example, if a participant added $250 \mathrm{mg}$ of $\mathrm{NaCl}$ to $250 \mathrm{ml}$ of the $-15 \%$ sodium-reduced soup, the amount of sodium added $=$ $0 \cdot 25 \times 39 \cdot 3=98 \mathrm{mg} \mathrm{Na} / 250 \mathrm{ml}$ soup. This amount was added to that in $250 \mathrm{ml}$ of $-15 \%$ sodium-reduced soup, which contained $648 \cdot 1 \mathrm{mg} \mathrm{Na} / 250 \mathrm{ml}$ soup. Thus the total amount of sodium $=648 \cdot 1 \mathrm{mg}+98 \mathrm{mg}=746 \cdot 1$ $\mathrm{mg} \mathrm{Na} / 250 \mathrm{ml}$ soup. The benchmark soup contained $762.5 \mathrm{mg} \mathrm{Na} / 250 \mathrm{ml}$ soup. The compensation percentage $=[(746 \cdot 1 / 762 \cdot 5) \times 100 \%]-100=-3 \%$. This means that after this participant added salt to the $-15 \%$ reducedsodium soup, the soup contained 3\% less sodium than the benchmark soup.

Friedman analyses (according to the within-subject design) for ranks and post hoc comparisons were conducted to determine if there were significant differences between the amounts of salt participants added after tasting soups with (i) different labels and (ii) different levels of sodium reduction. Statistics were performed with the statistical software package PASW Statistics version 18 (IBM, Armonk, NY, USA).

\section{Results}

\section{Participants}

The majority of participants were below the age of 40 years and well educated. More than half of the participants stated that health labels influenced their purchase decision (see Table 1).

\section{Expected liking and salt intensity}

Expected liking

All soups were expected to be liked, with scores between $4 \cdot 4$ and 5.3 on a 9-point hedonic scale. Participants tended to expect the soups with the reduced-salt label to be less liked than the same soups without labels $(0.05<P<0 \cdot 10)$. No statistically significant differences were observed between the different soups with the same

Table 1 Characteristics of the study participants

\begin{tabular}{lrr}
\hline Characteristic/category & Mean & SD \\
\hline Age (years) & & \\
Females $(n$ 33) & $35 \cdot 8$ & $14 \cdot 5$ \\
Males $(n$ 17) & $34 \cdot 4$ & $13 \cdot 3$ \\
& $n$ & $\%$ of total \\
\cline { 2 - 3 } & & \\
Education level & 7 & 14 \\
Secondary education or below & 19 & 38 \\
Tertiary education & 24 & 48 \\
Postgraduate or higher & & \\
Check the nutrition information when shopping & 14 & 28 \\
Always & 21 & 42 \\
Often & 4 & 8 \\
Sometimes & 0 & 0 \\
Rarely & 11 & 22 \\
Never & & \\
Labeling affects my food purchase & 11 & 22 \\
Always & 20 & 40 \\
Often & 2 & 4 \\
Sometimes & 1 & 2 \\
Rarely & 16 & 32 \\
Never & & \\
\hline
\end{tabular}


Table 2 Mean expected and perceived liking and salt intensity for the benchmark, $15 \%$ and $30 \%$ sodium-reduced soups with the three different labels

\begin{tabular}{|c|c|c|c|c|c|c|c|c|c|c|c|c|}
\hline & \multicolumn{6}{|c|}{ Expected liking before tasting } & \multicolumn{6}{|c|}{ Perceived liking after tasting } \\
\hline & \multicolumn{2}{|c|}{ Benchmark } & \multicolumn{2}{|c|}{$\begin{array}{l}15 \% \text { sodium } \\
\text { reduced }\end{array}$} & \multicolumn{2}{|c|}{$\begin{array}{l}30 \% \text { sodium } \\
\text { reduced }\end{array}$} & \multicolumn{2}{|c|}{ Benchmark } & \multicolumn{2}{|c|}{$\begin{array}{l}15 \% \text { sodium } \\
\text { reduced }\end{array}$} & \multicolumn{2}{|c|}{$\begin{array}{l}30 \% \text { sodium } \\
\text { reduced }\end{array}$} \\
\hline & Mean & SD & Mean & SD & Mean & $\mathrm{SD}$ & Mean & SD & Mean & SD & Mean & SD \\
\hline \multirow{6}{*}{$\begin{array}{l}\text { No label } \\
\text { Tick label } \\
\text { Reduced-salt label }\end{array}$} & $4 \cdot 9^{\mathrm{a}}$ & $1 \cdot 6$ & $5 \cdot 1^{\mathrm{a}}$ & 1.5 & $5 \cdot 3^{\mathrm{a}}$ & $1 \cdot 5$ & $4 \cdot 5^{a}$ & $1 \cdot 6$ & $4 \cdot 4^{a}$ & $1 \cdot 4$ & $4 \cdot 0^{\mathrm{a}}$ & $1 \cdot 2$ \\
\hline & $4 \cdot 8^{a, b}$ & $1 \cdot 3$ & $4 \cdot 8^{a}$ & $1 \cdot 4$ & $5 \cdot 2^{\mathrm{a}}$ & $1 \cdot 2$ & $4 \cdot 7^{\mathrm{a}}$ & $1 \cdot 1$ & $4 \cdot 3^{a}$ & 1.6 & $4 \cdot 0^{\mathrm{a}}$ & $1 \cdot 2$ \\
\hline & $4 \cdot 4^{\mathrm{b}}$ & $1 \cdot 5$ & $4 \cdot 5^{\mathrm{b} *}$ & $1 \cdot 3$ & $4 \cdot 8^{\mathrm{b} *}$ & $1 \cdot 4$ & $3 \cdot 9^{\mathrm{b}}$ & $1 \cdot 4$ & $5 \cdot 5^{\mathrm{b}}$ & $1 \cdot 6$ & $3 \cdot 8^{a}$ & $1 \cdot 2$ \\
\hline & \multicolumn{6}{|c|}{ Expected salt intensity before tasting (on JRS) } & \multicolumn{6}{|c|}{ Perceived salt intensity after tasting (on JRS) } \\
\hline & \multicolumn{2}{|c|}{ Benchmark } & \multicolumn{2}{|c|}{$\begin{array}{l}15 \% \text { sodium } \\
\text { reduced }\end{array}$} & \multicolumn{2}{|c|}{$\begin{array}{l}30 \% \text { sodium } \\
\text { reduced }\end{array}$} & \multicolumn{2}{|c|}{ Benchmark } & \multicolumn{2}{|c|}{$\begin{array}{l}15 \% \text { sodium } \\
\text { reduced }\end{array}$} & \multicolumn{2}{|c|}{$\begin{array}{l}30 \% \text { sodium } \\
\text { reduced }\end{array}$} \\
\hline & Mean & SD & Mean & SD & Mean & SD & Mean & SD & Mean & SD & Mean & SD \\
\hline No label & $6 \cdot 2+$ & $1 \cdot 4$ & $6 \cdot 3+$ & 1 & $6 \cdot 3+$ & $1 \cdot 4$ & $6 \cdot 8+$ & $1 \cdot 1$ & $4 \cdot 9$ & $1 \cdot 0$ & $4 \cdot 1+$ & $1 \cdot 0$ \\
\hline Tick label & $4 \cdot 3+$ & $1 \cdot 2$ & $4 \cdot 3 t$ & $1 \cdot 1$ & $4 \cdot 4+$ & $1 \cdot 2$ & $6 \cdot 2 t$ & 1.5 & $4 \cdot 8$ & $1 \cdot 4$ & $3 \cdot 6 t$ & $1 \cdot 1$ \\
\hline Reduced-salt label & $3.6 t$ & $1 \cdot 2$ & $3 \cdot 6 t$ & $1 \cdot 1$ & $3 \cdot 7 t$ & $1 \cdot \overline{1}$ & $5 \cdot 5 t$ & 1.5 & $4 \cdot 2 t$ & $1 \cdot 3$ & $3 \cdot 4 t$ & $1 \cdot 2$ \\
\hline
\end{tabular}

Liking was measured with a 9-point hedonic scale: $1=$ 'not liked at all' to $9=$ 'extremely liked'.

Salt intensity was measured with a just-about-right scale (JRS): $1=$ 'not salty enough at all', $5=$ 'just about the right amount of salt for me', $9=$ 'far too salty for me'.

${ }^{\mathrm{a}, \mathrm{b}}$ Mean values within columns with unlike superscript letters were significantly different, as measured with a repeated-measures ANOVA ( $\left.P<0 \cdot 05\right)$.

${ }^{\star}$ Reduced-salt label soups tended to be different from soups without a label $(P<0 \cdot 10)$.

tSignificantly different from the just-about-right salt intensity which was set at 5 , as measured with a one-sample $t$ test $(P<0 \cdot 05)$.

label in terms of expected liking across the $3 \mathrm{~d}$ of testing (see Table 2). Participants were more willing to buy the soups with the tick label (mean $5 \cdot 4$ (SD 1.6)) than the benchmark soups without such label (mean $4 \cdot 2$ (SD 1.4); $P<0 \cdot 01$ ).

\section{Expected salt intensity}

Participants expected the soups without health labels to be significantly above their ideal saltiness (mean range $6 \cdot 2$ to $6 \cdot 3$, i.e. too salty), whereas soups with health labels were expected to be significantly below their ideal saltiness (mean range 3.6 to 4.4 , i.e. not salty enough; all $P<0.05$ ). No significant differences in expected salt intensity were observed between the responses to the same packages on the three different days (see Table 2).

\section{Perceived liking and salt intensity}

\section{Perceived liking}

When participants actually tasted the soups a strong positive association between expected liking and perceived liking was observed for all soups across all labels (all $r$ between 0.44 and $0 \cdot 86$; all $P<0 \cdot 001$ ). Benchmark soups were medium liked (mean range 3.9 to $4 \cdot 7$ ) and significantly influenced by labels. That is, benchmark soups with the reduced-salt label were less liked (mean 3.9 (sD 1.4)) than similar soups with no label (mean 4.5 (sD $1 \cdot 6$ ); $P<0 \cdot 05$ ) or the tick label (mean $4 \cdot 7$ (sD $1 \cdot 1$; $P<0 \cdot 01)$. Soups which were $15 \%$ reduced in sodium and carried the reduced-salt label were more liked (mean $5 \cdot 5$ (sD 1.6)) than similar soups with no label (mean $4 \cdot 4$ (sD1.4); $P<0 \cdot 01$ ) or the tick label (mean 4.3 (SD 1.6); $P<0 \cdot 01$ ). Labels did not significantly influence participants' liking for soups which were $30 \%$ reduced in sodium. The soups which were $30 \%$ reduced in sodium and carried either the tick label $(P<0 \cdot 01)$ or no health label $(P<0 \cdot 01)$ were less liked than the benchmark soups with these labels. No such difference was observed for soups which carried the reduced-salt label (see Table 2).

\section{Perceived salt intensity}

All benchmark soups were perceived as significantly above participants' ideal salt concentration (mean range $5 \cdot 5$ to $6 \cdot 8$; $P<0 \cdot 05$ ). The benchmark soup with the reduced-salt label was perceived as significantly closer to participants' ideal salt intensity (mean 5.5 (SD 1.5)) than soups with either the tick label (mean 6.2 (sD 1.5); $P<0.05$ ) or no health label (mean 6.8 (sD 1.1); $P<0 \cdot 01$ ). The benchmark soup with the tick label was perceived as significantly closer to participants' ideal salt concentration than the same soup without a health label $(P<0 \cdot 05)$. Participants' expectations concerning salt intensity of the benchmark was significantly positively associated with their perceived salt intensity when the package did not carry the reduced-salt label (no label $r=0.50, P<0 \cdot 01$; tick label $r=0.32, P<0.05$; reduced-salt label $r=0 \cdot 14, P=0 \cdot 33$; see also Table 2).

When consumers tasted the $15 \%$ sodium-reduced soups, the soup with the reduced-salt label was perceived as significantly below participants' ideal salt concentration (mean 4.2 (sD 1.3); $P<0.001$ ), whereas the $15 \%$ sodium-reduced soup with the tick label (mean 4.8 (sD 1.4)) and that without a health label (mean 4.9 (SD 1.0)) were not perceived as significantly different from consumers' ideal salt concentration. Expected and perceived salt intensity of the $15 \%$ sodium-reduced soup were significantly positively associated when the package carried either the tick or the reduced-salt label (no label $r=0 \cdot 06$, 
$P=0 \cdot 66$; tick label $r=0 \cdot 39, P<0 \cdot 01$; reduced-salt label $r=0 \cdot 33, P<0 \cdot 05)$.

All $30 \%$ reduced-sodium soups were perceived as below consumers' ideal salt concentration (mean range

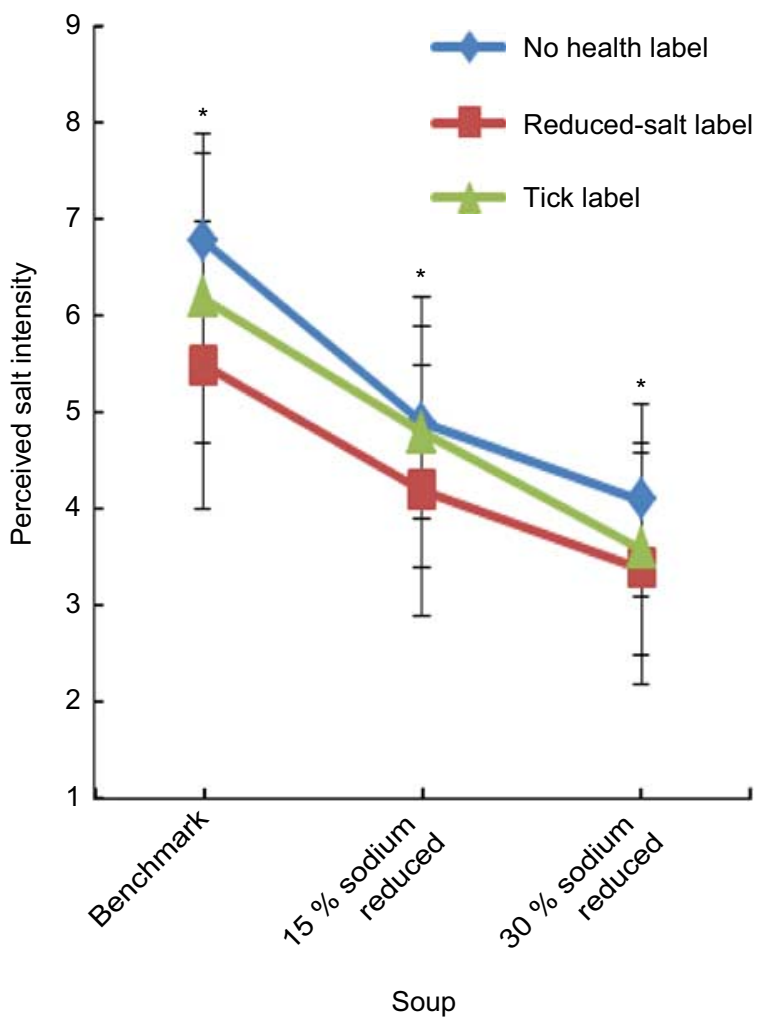

Fig. 3 (colour online) Participants' perceived salt intensity ( 1 = 'not salty enough at all', 5 = 'just about the right amount of salt for me', 9 = 'far too salty for me') for benchmark, $15 \%$ and $30 \%$ sodium-reduced soups with the three different labels (no health label, reduced-salt label and tick label). Values are means with their standard deviations represented by vertical bars. *Mean value was significantly different between soups with the same sodium content: $P<0.05$
$3 \cdot 4$ to $4 \cdot 1 ; P<0 \cdot 001)$. The soup with the reduced-salt label was, however, perceived as significantly further from consumers' ideal salt intensity (mean 3.4 (SD 1.2)) than the soups with either the tick label (mean $3 \cdot 6$ (SD $1 \cdot 1) ; P<0 \cdot 01$ ) or no health label (mean $4 \cdot 1$ (SD $1 \cdot 0$ ); $P<0 \cdot 01$; see Fig. 3). Overall, perceived salt intensity decreased with decreasing sodium concentration (all $P<0 \cdot 001)$. Expected and perceived salt intensity were strongly associated when the package carried the reduced-salt label, but not when other labels were present (no label $r=0 \cdot 28, P=0 \cdot 05$; tick label $r=0 \cdot 21$, $P<0 \cdot 15$; reduced-salt label $r=0 \cdot 66, P<0 \cdot 001)$.

\section{Adding salt}

The number of participants who added salt after tasting increased as the sodium reduction became larger (see Table 3). In addition, those who added salt to their soup generally added more salt when soups were further reduced in sodium. For every soup (i.e. benchmark, 15\% reduced in sodium, 30\% reduced in sodium), a greater number of participants added salt when the soup carried the reduced-salt label than when the same soup carried either the tick label or no health label. Those who added salt also added more salt when soups carried the reduced-salt label $(P<0 \cdot 05)$. When sodium was reduced by $30 \%$ and accompanied by the reduced-salt label participants over-compensated the reduction in salt; this resulted in $8 \%$ higher salt consumption than when they consumed the benchmark soup (see Table 3).

\section{Discussion}

The present study suggests that when consumers are able to taste the sodium reduction, a nutrient label which states 'now reduced in salt, great taste' magnifies the perceived difference in terms of ideal saltiness, and consumers add more salt.

Table 3 Average amount of salt added and number of participants who added salt to the benchmark, $15 \%$ and $30 \%$ sodium-reduced soups with the three different labels

\begin{tabular}{|c|c|c|c|c|c|c|}
\hline & \multirow[b]{2}{*}{$n^{*}$} & \multicolumn{2}{|c|}{ Salt added $(\mathrm{g}) \dagger$} & \multicolumn{2}{|c|}{$\% \mathrm{Na}$ added relative to benchmarkł } & \multirow{2}{*}{$\begin{array}{l}\text { Significance of } \\
\text { difference } \S\end{array}$} \\
\hline & & Mean & SD & Mean & SD & \\
\hline \multicolumn{7}{|l|}{ Benchmark } \\
\hline No label & 2 & 0.03 & 0.01 & 1.5 & $0 \cdot 7$ & $\|$ \\
\hline Tick label & 2 & $0 \cdot 47$ & 0.24 & $24 \cdot 0$ & $12 \cdot 3$ & \\
\hline Reduced-salt label & 8 & $0 \cdot 23$ & $0 \cdot 25$ & $11 \cdot 6$ & $12 \cdot 8$ & \\
\hline \multicolumn{7}{|l|}{$15 \%$ sodium reduced } \\
\hline No label & 14 & 0.25 & $0 \cdot 26$ & $-2 \cdot 0$ & $13 \cdot 6$ & $P<0.05$ \\
\hline Tick label & 15 & $0 \cdot 37$ & $0 \cdot 40$ & $4 \cdot 1$ & $20 \cdot 6$ & \\
\hline $\begin{array}{l}\text { Reduced-salt label } \\
30 \% \text { sodium reduced }\end{array}$ & 28 & $0 \cdot 36$ & $0 \cdot 19$ & $3 \cdot 5$ & $9 \cdot 8$ & \\
\hline \multicolumn{7}{|l|}{$30 \%$ sodium reduced } \\
\hline No label & 30 & 0.58 & 0.36 & -0.3 & $18 \cdot 3$ & $P<0.01$ \\
\hline Tick label & 35 & 0.57 & $0 \cdot 27$ & $-0 \cdot 8$ & $13 \cdot 9$ & \\
\hline Reduced-salt label & 46 & $0 \cdot 75$ & 0.32 & $8 \cdot 3$ & $16 \cdot 6$ & \\
\hline
\end{tabular}

*Number of participants who added salt out of 50 .

tAmount of salt added to $250 \mathrm{ml}$ soup, calculated for those who did add salt.

$\ddagger$ Calculated as $\{[(\mathrm{Na}$ added $+\mathrm{Na}$ in soup $) / \mathrm{Na}$ in benchmark $] \times 100 \%\}-100$.

$\S$ Significant difference between the labels as measured with a Friedman analysis for ranks.

॥No statistics were applied due to the low $n$. 
The effect of the reduced-salt label on perceived liking is less clear. Potentially the negative expectation, generated by the reduced-salt label, may have created a pleasant surprise when consumers tasted the sodium-reduced soup (i.e. 'It's not as bad as I thought it would be'). This contrast effect did not seem to take place when soups were further reduced in sodium, which elicited a clear perceivable difference with the benchmark, nor was the contrast effect evident when consumers were asked to rate ideal saltiness or when they were asked to add salt to optimize pleasantness of the soup. This may suggest that overall liking is influenced by more aspects than just saltiness.

Consumers can make a variety of foods more palatable by adding precise amounts of table salt ${ }^{(20-23)}$. Previous studies in which participants added salt to sodiumreduced meals suggested that consumers compensated only between $20 \%$ and $22 \%$ of the sodium which was left out of the meal ${ }^{(24,25)}$. This resulted in a meal with a lower salt concentration than the original non-sodium-reduced meal. In our study, consumers added larger amounts of salt to the sodium-reduced soups, which resulted in soups which contained about the same or higher amounts of salt than the non-sodium-reduced soup. However, these previous studies were conducted with whole meals where salt is more likely to be on the surface after it has been added from a salt shaker. This is in contrast with the present study where salt was added to a liquid (soup). It has previously been suggested that salt on the surface of the food will elicit a higher salt intensity than salt dissolved in food ${ }^{(26)}$.

It is important to note that only $28 \%$ of the participants added salt to the $15 \%$ sodium-reduced soups even though no additional flavour-enhancing ingredients were added by the manufacturer to compensate for the sodium reduction. This means that, when sodium reduction is compensated by other ingredients, a reduction of $15 \%$ in soups might be feasible as long as consumers are not being made aware of the sodium reduction. Currently, Unilever soups in Australia are in general 26\% lower in sodium than similar soups in the USA and $7 \%$ lower in sodium than in the UK. This suggests that soups in for example the USA could be lowered further in sodium, preferably in small incremental steps, so that the salt reduction is not perceived and consumer acceptance will be maintained.

The present study was carried out in a laboratory setting in which the information provided on the front of the pack had little competition from other stimuli which may attract consumers' attention in a real shopping and eating environment. Furthermore, our study sample consisted of consumers below the age of 40 years. These consumers might be more focused on taste and less focused on health than older consumers, because older aged consumers are more likely to have been in contact with a variety of chronic diseases ${ }^{(27)}$ and are more likely to check nutrient information while shopping ${ }^{(2)}$. It would therefore be worthwhile to repeat the present study with older consumers. Furthermore, our sample was in general highly educated, which could have increased the number of health-conscious consumers ${ }^{(28)}$.

To our knowledge, research suggesting that front-ofpack labelling influences food choice has generally been performed in markets in which a particular front-of-pack label has recently been introduced. Consumers may pay attention to these labels because they have been exposed to heavy marketing around the $\operatorname{logo}{ }^{(29)}$. Longitudinal studies in which the effectiveness of front-of-pack health logos is investigated over time are lacking to our knowledge. It could well be that, after a while, a front-ofpack logo loses the attention of consumers. Attention is driven by consumers' motivation, which is in line with their driver of purchase ${ }^{(29)}$. Future studies need to focus on the influence of front-of-pack health logos, such as the Heart Foundation Tick, on taste perception and liking in an in-home setting, not only initially, but also after repeated consumption over a longer time frame. Furthermore, it is recommended to assess the effectiveness of health labels on long-term food purchase and consumption in markets where these labels are no longer supported by marketing.

\section{Conclusions}

A label that explicitly notifies consumers of a reduction in sodium decreases the expected and perceived salt intensity, and may increase the use of table salt, especially when products are perceivably different in salt intensity. Overall health logos which do not emphasize the reduction in salt are less likely to affect perceived salt intensity and therefore are a viable solution to indicate the healthiness of sodium-reduced products. This is a relatively new area of research, but already it is beginning to deepen our understanding of how best to design and market healthy choices.

\section{Acknowledgements}

Source of funding: This research was funded by a Deakin Central Research Grant and supported by Unilever Research. Conflict of interest: E.H.Z. works as a research scientist at Unilever Research; D.G.L. is a senior lecturer at Deakin University, F.M. is an MSc student at Deakin University and R.S.J.K. is an associate professor at Deakin University. Authors' contributions: D.G.L. and F.M. contributed equally to the paper. D.G.L. was responsible for the design, data analyses and manuscript; F.M. carried out the study and contributed to the data analysis and manuscript writing; E.H.Z. was involved in the design and provided comments on earlier drafts of the manuscript; R.K. provided comments on earlier drafts of the manuscript. 
Acknowledgments: The authors would like to thank Megan Cobcroft, Katherine Cook and Katherine Tocchini for their technical assistance.

\section{References}

1. Worsley A \& Scott V (2000) Consumer's concerns about food and health in Australia and New Zealand. Asia Pac J Clin Nutr 9, 24-32.

2. Grimes C, Riddell L \& Nowson C (2009) Consumer knowledge and attitudes to salt intake and labelled salt information. Appetite 53, 189-194.

3. Williams P, Yeatman H, Zakrzewski S et al. (2003) Nutrition and related claims used on packaged Australian foods implications for regulation. Asia Pac J Clin Nutr 12, 138-150.

4. Chan C, Patch C \& Williams P (2005) Australian consumers are sceptical about but influenced by claims about fat on food labels. Eur J Clin Nutr 59, 148-151.

5. Food Standards Australia New Zealand (2011) Australia New Zealand Food Standards Code - Standard 1.2.8 Nutrition Information Requirements. Canberra: Commonwealth of Australia.

6. Feunekes GIJ, Gortemaker AI, Willems A et al. (2008) Front-of-pack nutrition labelling: testing effectiveness of different nutrition labelling formats front-of-pack in four European countries. Appetite 50, 57-70.

7. Higginson CS, Rayner MJ, Draper S et al. (2002) How do consumers use nutrition label information. Nutr Food Sci 32, $145-152$

8. Heart Foundation (2011) Heart Foundation Tick. http:// www.heartfoundation.org.au/healthy-eating/heart-foundationtick/pages/default.aspx (accessed February 2012).

9. Gander J \& Harding S (1999) National Heart Foundation Pick the Tick Research. Aukland: Research International.

10. Vyth EL, Steenhuis IHM, Vlot JA et al. (2010) Actual use of front-of-pack nutrition logo in supermarket: consumers' motives in food choice. Public Health Nutr 13, 1882-1889.

11. de Araujo IE, Rolls ET, Velazco MI et al. (2005) Cognitive modulation of olfactory processing. Neuron 19, 671-679.

12. Aaron JI, Mela DJ \& Evans RE (1994) The influence of attitudes, beliefs and label information on perception of reduced-fat spreads. Appetite 22, 25-37.

13. Yeomans MR, Lartamo S, Procter EL et al. (2001) The actual, but not labelled, fat content of a soup preload alters short-term appetite in healthy men. Physiol Behav 73, 533-540.
14. Liem DG, Toraman Aydin N et al. (2012) Effects of health labels on expected and actual taste perception of soup. Food Qual Pref (In the Press).

15. Kuenzel J, Zandstra EH, El-Deredy W et al. (2011) Expecting yoghurt drinks to taste sweet or pleasant increases liking. Appetite 56, 122-127.

16. Cardello AV, MacFie HJH \& Thomson DMH (1994) Consumer expectations and their role in food acceptance. In Measurement of Food Preferences, pp. 253-297 [HJH MacFie and DMH Thomson, editors]. London: Blackie Academic.

17. Lange C, Rousseau F \& Issanchou S (1999) Expectation, liking and purchase behaviour under economical constrains. Food Qual Pref 10, 31-39.

18. Meilgaard MC, Civille GV \& Carr BT (2007) Sensory Evaluation Technigues. Boca Raton, FL: Taylor \& Francis Group.

19. Lawless HT \& Heymann H (2010) Acceptance testing. In Sensory Evaluation of Food, pp. 327-347 [D Heldmann, editor]. New York: Springer.

20. Beauchamp GK (1987) The human preference for excess salt. Am Sci 75, 27-33.

21. Beauchamp GK (1997) Salt preference in humans. In Encyclopedia of Human Biology, pp. 669-675 [R Dulbecco, editor]. San Diego, CA: Academic Press.

22. Farleigh CA, Shepherd R \& Wharf SG (1990) The effect of manipulation of salt pot hole size on table salt use. Food Qual Pref 2, 13-20.

23. Lucas L, Riddell L, Liem G et al. (2010) The influence of sodium on liking and consumption of salty food. J Food Sci 76, issue 1, S72-S76.

24. Shepherd R, Farleigh CA \& Wharf SG (1989) Limited compensation by table salt for reduced salt within a meal. Appetite 13, 193-200.

25. Beauchamp GK, Bertino M \& Engelman K (1987) Failure to compensate decreased dietary sodium with increased table salt usage. JAMA 258, 3275-3278.

26. Shepherd R, Wharf SG \& Farleigh CA (2007) The effect of a surface coating of table salt of varying grain size on perceived saltiness and liking for paté. Int J Food Sci Technol 24, 330-340.

27. Vyth EL, Steenhuis IHM, Maillant SF et al. (2009) A front-ofpack nutrition logo: a quantitative and qualitative process evaluation in the Netherlands. J Health Commun 14, 631-645.

28. Roininen K (2001) Evaluation of Food Choice Behavior Development and Validation of Health and Taste Attitude Scales. Helsinki: University of Helsinki.

29. Bialkova Sl \& Van Trijp HC (2011) An efficient methodology for assessing attention to and effect of nutrition information displayed front-of-pack. Food Qual Pref 22, 592-601. 